\title{
TRATAMENTO JURÍDICO INTERNACIONAL DA CORRUPÇÃO: A CONVENÇÃO INTERAMERICANA CONTRA A CORRUPÇÃO DA O.E.A. E A CONVENÇÃO SOBRE O COMBATE DA CORRUPÇÃO DE FUNCIONÁRIOS PÚBLICOS ESTRANGEIROS EM TRANSAÇÕES COMERCIAIS INTERNACIONAIS DA O.C.D.E.
}

\begin{abstract}
Larissa O. Ramina
LLM Direito dos Negócios Internacionais, Professora de Direito Internacional das Faculdades do Brasil e das Faculdades Integradas Curitiba, Membro Convidado do Núcleo de Pesquisa em Direito Público do Mercosul.

SUMÁRIO: Introdução; 1 A corrupção como fenômeno de países em desenvolvimento e de países desenvolvidos; 2 A convenção interamericana contra a corrupção da O.E.A.; 3 A convenção sobre o combate da corrupção de funcionários públicos estrangeiros em transações comerciais internacionais e as recomendações da O.C.D.E.; Conclusões; Referências bibliográficas.
\end{abstract}

\section{INTRODUÇÃO}

O fenômeno da corrupção existe desde a Antigüidade como uma das formas de comportamento mais conflitantes com a boa administração dos interesses públicos. No entanto, com o passar dos tempos, circunstâncias históricas, políticas e econômicas têm alterado a sensibilidade pública frente a tais comportamentos. Na esfera internacional, a corrupção tem sido alvo de grande atenção nos últimos vinte e cinco anos, fazendo emergir consenso da comunidade internacional na urgência para ações concretas visando ao seu combate efetivo. A Assembléia Geral das Nações Unidas abordou o tema da corrupção em transações comerciais internacionais, pela primeira vez, na Resolução $n^{\circ} 3.514$, de 15 de dezembro de 1975 . Na constância da citada Resolução, numerosos instrumentos que consideram, no todo ou em parte, o tema da corrupção foram adotados por um amplo espectro de organizações internacionais, o que demonstra a tendência contemporânea no sentido de admitir uma certa medida de personalidade jurídica internacional dos indivíduos e das pessoas jurídicas de direito privado, as empresas transnacionais, já que são destinatários de normas previstas em instrumentos jurídicos internacionais.

As organizações internacionais regionais têm demonstrado um esforço de colaboração no sentido de promover a cooperação global para a criminalização da corrupção transnacional, tanto em países em desenvolvimento, quanto em países exportadores de capital. A corrupção transnacional aqui se refere àqueles atos praticados 
por empresas transnacionais sediadas em países desenvolvidos com o intuito de corromper funcionários públicos estrangeiros originários de países em desenvolvimento. Ademais, essas organizações internacionais regionais têm se esforçado para promover a cooperação internacional na investigação e persecução de crimes econômicos transnacionais, como por exemplo a lavagem de dinheiro; e, para coletar informações sobre as experiências realizadas em outros países, fornecendo treinamento para governos que não possuam experiência no trato da corrupção. Entre as organizações internacionais de caráter regional participantes desta iniciativa, merecem destaque a Organização dos Estados Americanos (O.E.A.) e a Organização para Cooperação e Desenvolvimento Econômico (O.C.D.E.), cujos instrumentos adotados serão objeto do presente trabalho. Uma breve abordagem dos aspectos culturais da corrupção precederá a esta análise.

\section{A CORRUPÇÃO COMO FENÔMENO DE PAÍSES EM DESENVOLVIMENTO E DE PAÍSES DESENVOLVIDOS}

A corrupção é um fenômeno multidimensional que possui dimensões econômicas, políticas, sociais, legais, administrativas e culturais. De acordo com o Programa das Nações Unidas para o Desenvolvimento (P.N.U.D.), o argumento relativo às "diferenças culturais" não pode justificar o fornecimento de propinas. É verdade que em muitos países a corrupção se tornou o modo mais comum de praticar atos negociais; todavia, práticas comuns não merecem ser confundidas com aceitação cultural e logo o uso indevido da coisa pública não pode ser visto como uma prática cultural. Ora, se a corrupção fosse efetivamente um fenômeno cultural, ela não seria considerada ilegal em todas as partes do mundo. ${ }^{1}$

$\mathrm{Na}$ verdade, parte significativa da corrupção nos países em desenvolvimento é importada. Existem muitos países nos quais a corrupção não constituía um problema importante, não fosse a participação ativa de investidores estrangeiros. $\mathrm{O}$ crime organizado está envolvido neste processo, mas, geralmente, os pagadores de propina são empresas transnacionais cuja reputação é, aparentemente, boa. Ademais, muitos países industrializados tratavam o fornecimento de propinas além das fronteiras nacionais como despesas passíveis de dedução fiscal. Após a entrada em vigor da Convenção sobre o Combate da Corrupção de Funcionários Públicos Estrangeiros em Transações Comerciais Internacionais, os Países-membros da O.C.D.E. concordaram na nãodedução fiscal dessas propinas.

Como conseqüência, o conceito de que a corrupção é controlável somente nos casos das nações industrializadas não é sustentável. Embora exista correlação entre o grau de desenvolvimento e o grau de corrupção nos níveis administrativo e burocrático, também é verdadeiro dizer que existem muitas diferenças entre a incidência de corrupção em países que estão no mesmo patamar de desenvolvimento. A Transparência Internacional, organização não-governamental de caráter econômico, cuja principal finalidade é combater a corrupção no mundo, em suas pesquisas, classificou o Chile, a República Tcheca, a Malásia, a Polônia e a África do Sul como países mais transparentes 
que a Grécia e a Itália, países ditos industrializados. ${ }^{2}$ Além disso, estes índices de percepção do grau de corrupção não incorporam o efeito da corrupção nos sistemas políticos e a propensão dos investidores dos países industrializados para oferecer propinas no exterior. A Transparência Internacional também sugere que a corrupção no setor público possui as mesmas formas e afeta as mesmas áreas tanto em nações em desenvolvimento quanto em nações desenvolvidas.

Conseqüentemente, embora existam várias causas internas para a corrupção, seus níveis não são determinados apenas domesticamente, mas a responsabilidade deve ser dividida com outros sujeitos, principalmente as empresas transnacionais, que constituem a maior fonte de propinas em nível global. O mito de que a corrupção é uma praga dos países em desenvolvimento deve, portanto, ser totalmente descartado.

\section{A CONVENÇÃO INTERAMERICANA CONTRA A CORRUPÇÃO DA O.E.A.}

A Convenção Interamericana contra a Corrupção ${ }^{3}$ representa o primeiro instrumento internacional a tratar do tema da corrupção transnacional e constitui o exemplo pioneiro de ação jurídica regional no mundo em desenvolvimento. As negociações para adoção do tratado foram concluídas em 29 de março de 1996, e sua entrada em vigor ocorreu em 7 de março de 1997. Até o presente momento, vinte e oito países assinaram a Convenção, entre os quais está o Brasil, que procedeu a sua assinatura em 29 de março de 1996. Destes, apenas vinte e três países depositaram seus instrumentos de ratificação junto ao secretariado geral da O.E.A., a saber: Paraguai, Bolívia, Peru, Costa Rica, Venezuela, Equador, México, Argentina, Trinidad e Tobago, Honduras, Panamá, Chile, El Salvador, Uruguai, Colômbia, Nicarágua, República Dominicana, Bahamas, Canadá, Jamaica, Estados Unidos da América, Guiana e Guatemala. São Vicente e Granadinas depositou seu instrumento de adesão ao tratado. No Brasil, a Convenção se encontra atualmente em trâmite no Congresso Nacional, de acordo com o art. 49, inciso I da Constituição Federal.

A Convenção Interamericana contra a Corrupção identifica os atos de corrupção para os quais serão aplicadas as disposições do texto, criando, assim, obrigações segundo o direito internacional, assim como princípios, na luta contra a corrupção. A Convenção também prevê o desenvolvimento institucional e a implementação de mecanismos

2 www.transparency.de. Ainda segundo esta $\mathrm{ONG}$, o Brasil ocupa a 46 a posição no ranking dos países mais íntegros, numa lista de 91 pesquisados. De zero a dez, tirou quatro no corrente ano. As notas são atribuídas aos países em pesquisa com executivos e empresários. Cerca de $4 \%$ dos entrevistados no Brasil disseram já ter recebido propostas de propinas de funcionários públicos. Em Portugal, por exemplo, essa percentagem é de $1,4 \%$. Em outra pesquisa, a Transparência Brasil constatou que $6 \%$ dos eleitores brasileiros, cerca de 6 milhões de pessoas, foram abordados por políticos para vender seus votos nas eleições municipais do ano passado. Desse total, $31 \%$ aceitaram o suborno. Entre os que aceitaram, $25 \%$ votaram no candidato desonesto.

3 O texto da Convenção Interamericana contra a Corrupção pode ser encontrado na versão em português no endereço eletrônico da O.E.A.: www.oas.org. 
anticorrupção, incluindo a assistência recíproca nas áreas jurídica e técnica. Ademais, prevê procedimentos de cooperação para a extradição, seqüestro de bens e assistência legal e técnica recíproca quando atos de corrupção ocorram ou produzam efeitos em uma das partes. Adicionalmente, sujeita às suas respectivas Constituições e aos princípios fundamentais de seus sistemas legais, a Convenção requer às partes a criminalização dos atos de corrupção de funcionários públicos estrangeiros. A Convenção contém também uma série de "medidas preventivas" que as partes concordam em considerar para prevenir a corrupção, incluindo sistemas de compras governamentais comprometidos com a publicidade, eqüidade e eficiência.

O escopo da Convenção da O.E.A. inclui a implementação, pelos Estados, de mecanismos de prevenção, investigação, punição e erradicação da corrupção, assim como sua cooperação no sentido de assegurar a eficácia de tais mecanismos. ${ }^{4}$

A Convenção dirige-se à corrupção no exercício das funções públicas, ${ }^{5}$ tendo assim abrangência mais ampla que aquela prevista pelo instrumento da O.C.D.E. sobre a corrupção de funcionários públicos estrangeiros. A diferença conceitual está no fato de que a O.C.D.E. representa os Estados desenvolvidos, enquanto que os membros da O.E.A. são, em sua maioria, Estados em desenvolvimento. Por esta razão, em contraste com a Convenção da O.C.D.E., a qual dá importância à corrupção ativa, a Convenção da O.E.A. prevê os dois aspectos da corrupção, tanto o ativo quanto o passivo. ${ }^{6} \mathrm{~A}$ definição de atos de corrupção constante da Convenção da O.E.A. é ampla, sendo irrelevante o dano causado, que pode lesar a propriedade pública ou não, ${ }^{7}$ os motivos pelos quais foram praticados, podendo ser políticos ou não, ou os propósitos. ${ }^{8}$ Ademais, assim como a Convenção da O.C.D.E., o instrumento da O.E.A. prevê a criminalização de co-autores, instigadores, cúmplices e acobertados. ${ }^{9}$ Contém, também, uma disposição acerca do suborno transnacional, ${ }^{10}$ que coincide com a corrupção ativa de funcionários públicos estrangeiros prevista pelo instrumento da O.C.D.E., e outra relativa ao crime de enriquecimento ilícito, ${ }^{11}$ considerado igualmente um ato de corrupção.

As definições de "funcionário público", "funcionário de governo" e "servidor público", dadas pela Convenção da O.E.A. são amplas, assim como a definição de "função pública". ${ }^{12}$

De acordo com a Convenção Interamericana, o Estado assumirá jurisdição quando a ofensa for cometida em seu território ou quando o acusado estiver presente

4 Convenção Interamericana contra a Corrupção, art. II.

5 Convenção Interamericana..., preâmbulo.

6 Convenção Interamericana..., art. VI.

7 Convenção Interamericana..., art. XII.

8 Convenção Interamericana..., art. XVII

9 Convenção Interamericana..., art. VI.

10 Convenção Interamericana..., art. VIII.

11 Convenção Interamericana..., art. IX.

12 Convenção Interamericana..., art. I. 
em seu território e não puder ser extraditado devido a sua nacionalidade $;^{13}$ e poderá, também, assumir jurisdição quando a ofensa for cometida por um de seus nacionais ou por uma pessoa que tenha residência habitual em seu território. ${ }^{14} \mathrm{O}$ texto prevê também um artigo sobre extradição. ${ }^{15}$

Finalmente, a Convenção contém disposições acerca da assistência recíproca e cooperação, ${ }^{16}$ sigilo bancário (o que não pode ser fundamento para a recusa de assistência) ${ }^{17}$ medidas preventivas ${ }^{18} \mathrm{e}$ desenvolvimento progressivo. ${ }^{19} \mathrm{O}$ último revela práticas comuns de países em desenvolvimento, como, por exemplo, o uso ou aproveitamento indevido, em benefício próprio ou de terceiros, por parte de funcionário público, de bens públicos. ${ }^{20}$

A Convenção engloba um amplo elenco de práticas corruptas, incluindo desde a corrupção puramente doméstica até a corrupção transnacional. Logo, seu escopo é consideravelmente mais amplo do que aquele da Convenção da O.C.D.E. A Convenção da O.E.A. requer legislações nacionais que criminalizem os atos de proposta, solicitação e aceitação de propinas por funcionários públicos nacionais; logo, cobre os dois lados do crime. Ademais, prevê que os Estados adotem medidas legislativas e outras, com o intuito de criminalizar os atos de corrupção descritos no art. VI. Entretanto, os Estados não possuem os mesmos deveres em relação à corrupção internacional e ao enriquecimento ilícito. A Convenção é mais flexível quando prevê o crime de enriquecimento ilícito, já que dispõe que "os Estados-partes adotarão as medidas necessárias para tipificar como delito em sua legislação o aumento do patrimônio de um funcionário público que exceda de modo significativo sua renda legítima durante o exercício de suas funções e que não possa justificar razoavelmente, sem prejuízo de sua Constituição e dos princípios fundamentais de seu ordenamento jurídico". ${ }^{21}$

A Assembléia Geral da O.E.A. adotou um plano contra a corrupção, complementar à Convenção, em seu encontro em Lima, em junho de 1997. De acordo com este plano, a Organização deve disponibilizar apoio aos Estados-membros e cooperar com populações locais e outras organizações internacionais - incluindo a O.C.D.E. - para prevenir e extirpar a corrupção.

13 Convenção Interamericana..., art. V.

14 A Convenção da O.C.D.E. contra a Corrupção não inclui a expressão "residentes" na parte relativa à jurisdição.

15 Convenção Interamericana..., art. XIII.

16 Convenção Interamericana..., art. XIV.

17 Convenção Interamericana..., art. XV.

18 Convenção Interamericana..., art. III.

19 Convenção Interamericana..., art. XI.

20 Convenção Interamericana..., art. XI, (b).

21 Convenção Interamericana..., art. IX, itálico do autor. 


\section{A CONVENÇÃO SOBRE O COMBATE DA CORRUPÇÃO DE FUNCIONÁRIOS PÚBLICOS ESTRANGEIROS EM TRANSAÇÕES COMERCIAIS INTERNACIONAIS E AS RECOMENDAÇÕES DA O.C.D.E. ${ }^{22}$}

A Organização para Cooperação e Desenvolvimento Econômico conta com vinte e nove Estados-membros ${ }^{23}$ os quais constituem os principais países em termos de comércio internacional e fluxos de investimento. Uma das primeiras iniciativas da O.C.D.E. em termos de ação anticorrupção ocorreu em 1976, quando a organização publicou a Declaração sobre Investimento Internacional e Empresas Multinacionais, a qual incluiu as Diretrizes para Empresas Multinacionais. As Diretrizes prevêem que "as empresas não deveriam conceder ou ser solicitadas a conceder qualquer espécie de propina ou outros benefícios, direta ou indiretamente, a quaisquer funcionários públicos". Embora as Diretrizes tenham sido revisadas em 1979, 1984 e 1991, nenhuma modificação focalizou na parte relativa à corrupção. De qualquer forma, não constituem um instrumento internacional dotado de força jurídica obrigatória, mas tão-somente um instrumento que parte da doutrina classifica como do gênero soft law. ${ }^{24}$

Em 1994, a O.C.D.E. adotou a Recomendação sobre o Combate da Corrupção em Transações Comerciais Internacionais, e, em 1996, a Recomendação sobre Dedução Fiscal de Propinas pagas a Funcionários Públicos Estrangeiros. Uma Recomendação revisada sobre o Combate da Corrupção em Transações Comerciais Internacionais foi aprovada em maio de 1997, iniciando as negociações para uma convenção internacional que criminalizasse a corrupção. Em 1996, a O.C.D.E. adiantou-se na eliminação das práticas relativas à dedução fiscal de propinas mediante a adoção da Recomendação sobre a Dedução Fiscal de Propinas pagas a Funcionários Públicos Estrangeiros.

Em maio de 1997, a Organização também estabeleceu um roteiro para que os Estados-membros atingissem o objetivo de criminalização da corrupção transnacional. Estes então concordaram desde logo em iniciar a negociação para uma convenção acerca da corrupção transnacional, em conformidade com um já acordado elenco de elementos comuns para guiar a elaboração de suas legislações criminais e em introduzir legislações anticorrupção em nível doméstico, baseadas nos elementos comuns acordados. Aos 21 de novembro de 1997, negociadores provenientes de 34 países (os 29 Estados-membros

22 A Convenção sobre o Combate da Corrupção de Funcionários Públicos Estrangeiros em Transações Comerciais Internacionais e as Recomendações da O.C.D.E. podem ser encontradas no site da organização nas versões em inglês e francês, www.oecd.org.

23 Os Estados-membros da O.C.D.E. são: Alemanha, Austrália, Áustria, Bélgica, Canadá, Coréia, Dinamarca, Espanha, Estados Unidos, Finlândia, França, Grécia, Holanda, Hungria, Irlanda, Islândia, Itália, Japão, Luxemburgo, México, Noruega, Nova Zelândia, Polônia, Portugal, Reino Unido, República Tcheca, Suécia, Suíça e Turquia.

24 Apesar de parte da doutrina se referir à instrumentos de soft law como "direito flexível", parece não se tratar de instrumento jurídico. A classificação do direito em "direito flexível" e "direito rígido" (hard law) não é adequada. 
da O.C.D.E. e outros 5 países (Argentina, Brasil, Bulgária, Chile e Eslováquia) adotaram em Paris a Convenção sobre o Combate da Corrupção de Funcionários Públicos Estrangeiros. A Convenção foi assinada em 17 de dezembro de 1997 e entrou em vigor em 15 de fevereiro de 1999, portanto posteriormente à adoção da Convenção da O.E.A. Esse instrumento constitui uma conquista histórica na luta contra a corrupção transfronteiriça.

Até abril de 2001, trinta e dois países haviam depositado os respectivos instrumentos de ratificação ou aceitação da Convenção, sendo eles: Islândia, Japão, Alemanha, Hungria, Estados Unidos, Finlândia, Reino Unido, Canadá, Noruega, Bulgária, Coréia, Grécia, Áustria, México, Suécia, Bélgica, Eslováquia, Austrália, Espanha, República Tcheca, Suíça, Turquia, França, Dinamarca, Polônia, Portugal, Itália, Holanda, Argentina, Luxemburgo e Chile. O Brasil ratificou a Convenção em 24 de agosto de 2000. No entanto, a Convenção está aberta a qualquer país que se torne participante do Grupo de Trabalho para a Corrupção. Alguns Estados, como Israel, Rússia, Croácia, Romênia e Letônia, também demonstraram interesse em fazer parte da Convenção.

A Convenção focaliza no tema da corrupção de funcionários públicos estrangeiros. A corrupção de funcionários públicos nacionais já constituía crime de acordo com as legislações domésticas dos Países-membros, assim como na maior parte dos países do globo. O foco situa-se no indivíduo que oferece, promete ou dá a "propina" - ou seja - na corrupção ativa, em contraste com a corrupção passiva. ${ }^{25}$ A Convenção representa um esforço para eliminar o fornecimento de propinas a funcionários públicos estrangeiros, sendo que cada país responsabiliza-se pelas atividades das empresas que atuam em território nacional. Ademais, a Convenção procura assegurar equivalência entre as sanções aplicadas em nível nacional e aquelas aplicadas à corrupção de funcionários públicos estrangeiros, sem contudo exigir uniformidade ou mudanças nos princípios fundamentais das ordens jurídicas nacionais.

A definição de corrupção, no escopo da Convenção, é ampla. ${ }^{26}$ Prevê-se que a corrupção de um funcionário público estrangeiro constitui uma ofensa independentemente daquilo que é oferecido, prometido ou dado, se expresso em vantagem pecuniária indevida ou de outra natureza, não importando se a propina é fornecida diretamente ou através de intermediários, ou ainda se o beneficiário é o próprio funcionário ou um terceiro. Também é irrelevante o fato de a empresa receber em troca um contrato comercial ou qualquer outro tipo de vantagem imprópria, como atos administrativos de concessão, autorização ou permissão. Cúmplices ou, em outras palavras, quaisquer pessoas que incitam, auxiliam ou encorajam um ato de corrupção

25 De acordo com os Comentários à Convenção sobre o Combate da Corrupção de Funcionários Públicos Estrangeiros em Transações Comerciais Internacionais, o termo "corrupção ativa" não foi usado para evitar que o leitor leigo entenda que o corruptor toma a iniciativa e o receptor meramente se comporta como vítima pacífica. Os Comentários dão exemplos de casos nos quais a iniciativa parte do receptor.

26 Convenção sobre o Combate da Corrupção de Funcionários Públicos Estrangeiros em Transações Comerciais Internacionais, art. $1^{\circ}$, http://www.oecd.org. 
de funcionário público estrangeiro devem ser considerados incursos na mesma figura criminal. A tentativa e a conspiração, se criminalizados segundo o direito nacional, devem também ser consideradas ofensas criminais. ${ }^{27}$

A definição de funcionário público estrangeiro é igualmente $\operatorname{ampla}^{28} \mathrm{e}$ extensiva a qualquer pessoa responsável por cargo legislativo, administrativo ou jurídico de um país estrangeiro, eleito ou nomeado, ou exercendo qualquer função pública para um país estrangeiro. "Função pública" inclui qualquer atividade em consonância com o interesse público. De acordo com a Convenção, a autoridade pública estrangeira pode ser o mandatário de empresa pública ou de qualquer outro monopólio estatal, ou quaisquer outros indivíduos que prestem serviços em empresas nas quais governos tenham participação societária dominante. ${ }^{29}$

A Convenção também prevê que "a parte que tornou o delito de corrupção de seu próprio funcionário público um delito declarado para o propósito da aplicação de sua legislação sobre lavagem de dinheiro deverá fazer o mesmo, nos mesmos termos, em relação à corrupção de um funcionário público estrangeiro, sem considerar o local de ocorrência da corrupção". ${ }^{30}$

De acordo com a Convenção, os países que possuem, em seus sistemas legais, a previsão normativa de responsabilidade criminal de pessoas jurídicas estão aptos a iniciar procedimentos criminais contra as empresas envolvidas em atos de corrupção. ${ }^{31}$ Quando o sistema legal não previr tal tipo legal, a responsabilidade extrapenal das pessoas jurídicas deve ser efetivamente imposta, através de sanções efetivas e proporcionais, incluindo penalidades financeiras. ${ }^{32}$ As empresas engajadas em atos de corrupção devem assumir o risco de terem suas imagens comprometidas, fator que pode ser bastante dissuasivo.

Adicionalmente, a Convenção requer que os países imponham sanções criminais que sejam efetivas, proporcionais e dissuasivas, incluindo privação de liberdade no caso de pessoas físicas, ${ }^{33}$ considerando-se, inclusive, a aplicação de sanções civis e administrativas. ${ }^{34}$

27 Convenção sobre o Combate da Corrupção..., art. $1^{\circ}, \S 2^{\circ}$. Os Comentários à Convenção sobre o Combate da Corrupção de Funcionários Públicos Estrangeiros afirmam que os pagamentos para facilitar a tramitação administrativa não são considerados ofensas de acordo com a Convenção. Em grande número de países, tais pagamentos já são considerados ilícitos, e a Convenção incita todos os países a lutar contra esta forma de corrupção.

28 Convenção sobre o Combate da Corrupção..., art. $1^{\circ}$.

29 Os Comentários à Convenção sobre o Combate da Corrupção ... prevêem que em circunstâncias especiais, cargos de autoridades podem ser exercidos por pessoas despossuídas de título público.

30 Convenção sobre o Combate da Corrupção..., art. $7^{\circ}$.

31 Convenção sobre o Combate da Corrupção..., art. $2^{\circ}$.

32 Convenção sobre o Combate da Corrupção..., art. $3^{\circ}(2)$.

33 Convenção sobre o Combate da Corrupção..., art. $3^{\circ}(1)$.

34 Convenção sobre o Combate da Corrupção..., art. $3^{\circ}$ (4). De acordo com os Comentários à Convenção, entre as sanções civis e administrativas, podem também ser impostas a pessoas jurídicas a exclusão de 
De acordo com a Convenção da O.C.D.E., a jurisdição territorial deve ser interpretada de maneira ampla a permitir que não seja requerida uma conexão física substancial com o ato de corrupção. Quando mais de um país possua jurisdição em relação à ofensa criminal, os países envolvidos deverão determinar diplomaticamente aquela mais apropriada para os efeitos de processo judicial. ${ }^{35}$

A investigação e a denúncia de corrupção de funcionário público estrangeiro, com base na Convenção, não devem sofrer considerações de natureza política. ${ }^{36}$ Esta previsão foi revisada pelo $\S 6^{\circ}$ do Anexo à Recomendação revisada da O.C.D.E. de 1997 sobre o Combate da Corrupção em Transações Comerciais Internacionais, a qual recomenda, inter alia, que as autoridades competentes devem investigar seriamente as denúncias de corrupção de funcionários públicos estrangeiros, e que os governos disponham de recursos a fim de permitir o devido processo criminal. O monitoramento dos termos da Convenção está relacionado à Seção V da Recomendação de 1997. ${ }^{37}$

A previsão relacionada à prestação de contas requer que os Estados participantes da Convenção adotem medidas direcionadas ao arquivo de livros e registros contábeis, divulgação de declarações financeiras e sistemas de contabilidade e auditoria, a fim de proibir mecanismos de contabilidade paralela, ou o "caixa dois" (simulação de transações inexistentes, despesas nunca realizadas, uso de documentos falsos para ocultar propinas etc.). ${ }^{38}$

A Convenção ainda prevê assistência jurídica recíproca para o fim de condução de investigações criminais e demais procedimentos correlatos instaurados pela parte sobre delitos abrangidos pela Convenção e, também, para ações civis. ${ }^{39}$ Também é prevista a fundamentação jurídica de extradição com base na Convenção, caso os Estados participantes requeiram, de acordo com a legislação doméstica, um tratado permitindo a extradição de criminosos. ${ }^{40} \mathrm{~A}$ cooperação entre os países é encorajada através de contato regular com o Grupo de Trabalho da O.C.D.E. para a corrupção, ${ }^{41}$ chamandose a atenção dos Estados-membros para criarem um mecanismo de monitoramento e acompanhamento da implementação da Convenção. ${ }^{42}$

benefícios públicos, desqualificação temporária ou definitiva para participação em contratos administrativos e supervisão judicial.

35 Convenção sobre o Combate da Corrupção..., art. $4^{\circ}$ (3).

36 Convenção sobre o Combate da Corrupção..., art. $5^{\circ}$.

37 Comentários à Convenção sobre o Combate da Corrupção... De acordo com os Comentários, uma conseqüência imediata da implementação da Convenção será que as empresas obrigadas a prestar contas deverão prestar atenção nos dispositivos relativos à responsabilidade civil, particularmente em relação às sanções e à contabilidade. Adicionalmente, as ofensas contábeis geralmente são praticadas no país de origem, sendo que os atos de corrupção ocorreram em país estrangeiro.

38 Convenção sobre Combate da Corrupção..., art. $8^{\circ}$.

39 Convenção sobre o Combate da Corrupção..., art. $9^{\circ}$.

40 Convenção sobre o Combate da Corrupção..., art. 10.

41 Atualmente, o Grupo de Trabalho está examinando atos de corrupção em partidos políticos estrangeiros, incluindo candidatos para trabalhos diplomáticos e corrupção através de subsidiárias estrangeiras, entre outros. O Grupo está particularmente interessado nos paraísos fiscais. Disponível em: http:// www.oecd.org.

42 Convenção sobre o Combate da Corrupção..., art. 12. 
Os objetivos da Convenção foram ainda reforçados pelas Recomendações da O.C.D.E. A Recomendação revisada da O.C.D.E. para o Combate da Corrupção em Relações Comerciais Internacionais, da qual fazem parte os países que assinaram a Convenção, apela para a tomada de medidas efetivas na prevenção e no combate da corrupção, incluindo recomendações concernentes à dedução fiscal de propinas, prestação de contas, contratos administrativos, cooperação internacional e arranjos institucionais. Essas medidas obrigam as empresas a manterem banco de dados relativos à contabilidade e a adotarem controles internos. $\mathrm{Na}$ área de compras governamentais, é recomendado que as empresas declaradas culpadas por corrupção de funcionários públicos estrangeiros sejam proibidas de participar em novos certames públicos. Além disso, os países devem colaborar nas investigações e em outros mecanismos legais, com o objetivo de conferir eficácia jurídica em casos nos quais se constate a corrupção de funcionários públicos estrangeiros.

Até recentemente, em alguns países, empresas privadas podiam requerer a dedução fiscal de propinas pagas a funcionários públicos estrangeiros, não obstante a ilegalidade de tais atos. A Recomendação da O.C.D.E. de 1996 sobre a Dedução Fiscal de Propinas exige que os países reexaminem os critérios de concessão da referida dedução, tratando-se do fornecimento de propinas. O Comitê Fiscal da O.C.D.E. é responsável pelo controle de tal exigência e recentemente divulgou um relatório afirmando que nenhum dos países da O.C.D.E. permite, atualmente, tal procedimento. Em alguns países, a adoção da Convenção possibilitou a introdução de instrumentos legislativos que vedassem tais práticas espúrias.

A Recomendação sobre o Combate da Corrupção em Licitações Financiadas por Terceiros, por sua vez, chama a atenção dos países no sentido de atender a critérios específicos de controle da corrupção em casos de financiamento de contratos administrativos por terceiros, como, por exemplo, bancos de fomento econômico.

Finalmente, a Recomendação da O.C.D.E. de 1998 sobre a Ética no Serviço Público reforça os objetivos da Convenção e incita os países para que estes tomem medidas para assegurar o correto funcionamento das instituições e sistemas de promoção de conduta ética no serviço público, enfatizando o trabalho da Equipe Financeira para a Lavagem de Dinheiro, a qual constitui uma agência intergovernamental que tem como objetivo o desenvolvimento e a promoção de políticas no combate à lavagem de dinheiro - procedimentos criminais destinados a disfarçar sua origem ilícita.

Além de ser o órgão depositário da Convenção sobre o Combate da Corrupção de Funcionários Públicos Estrangeiros, a O.C.D.E. possui uma estrutura institucional para assegurar o monitoramento e o cumprimento da Convenção. Essa função é exercida em uma unidade localizada no Diretório para Assuntos Empresariais, Fiscais e Financeiros. Ademais, a O.C.D.E. gerencia um Centro de Informações Anticorrupção para economias em transição.

Os Estados-partes adotaram a legislação necessária para a implementação da Convenção junto ao direito nacional; em outras palavras, para criminalizar a corrupção de funcionários públicos estrangeiros. Um processo de monitoramento e de vigilância foi posto em prática no sentido de examinar a legislação de cada país e a respectiva 
conformidade com os termos da Convenção. O Grupo de Trabalho avalia o desempenho de cada país e faz as recomendações necessárias às autoridades competentes dos Estados.

Alguns países que já são partes da Convenção ainda não adotaram as respectivas legislações nacionais de transposição. Entre eles está o Brasil.

No direito pátrio, o projeto de lei de transposição da Convenção, que propõe uma alteração no Código Penal, foi concluído e aprovado pelo Presidente, que submeteu o projeto à apreciação do Congresso Nacional em 20 de fevereiro de 2001. O projeto de lei estabelece medidas contra o crime de lavagem de dinheiro, prevendo a atribuição de tipicidade penal à corrupção ativa em transações comerciais internacionais, assim como ao tráfico de influência em transação comercial internacional, especificando-se o que a legislação considera funcionário público estrangeiro para efeitos penais. O projeto foi submetido à apreciação da Comissão de Constituição e Justiça e de Redação (CCJR) da Câmara dos Deputados, que o aprovou em 18 de outubro deste ano.

A aprovação dessa matéria é uma demonstração do esforço da Câmara na criação de instrumentos de combate ao crime organizado e à corrupção no país. O projeto será submetido em caráter de urgência ao plenário da Câmara antes de ir ao Senado. O Presidente da Câmara, AÉCIO NEVES, afirmou que a tramitação do projeto foi acelerada a pedido do Ministro das Relações Exteriores, CELSO LAFER, segundo o qual a diplomacia brasileira estava sendo cobrada por outros países para implementar a Convenção. ${ }^{43}$

O projeto estabelece pena de reclusão de um a oito anos e multa para quem prometer, oferecer ou der, direta ou indiretamente, vantagem indevida a funcionário público estrangeiro ou a terceira pessoa para determiná-la a praticar, omitir ou retardar atos e ofícios relacionados à transação comercial internacional. Estabelece, ainda, pena de reclusão de dois a cinco anos e multa para quem solicitar, exigir, cobrar ou obtiver, para si ou para outrem, direta ou indiretamente, vantagem ou promessa de vantagem, a pretexto de influir em ato praticado por funcionário público estrangeiro no exercício de suas funções, relacionada à transação comercial internacional.

O projeto considera funcionário público estrangeiro, para efeitos penais, aquele que, ainda que transitoriamente ou sem remuneração, exerça cargo, emprego ou função pública em entidade estatal ou em representação diplomática de país estrangeiro. Esperase que o Congresso adote o projeto de lei antes do final do ano de 2001.

\section{CONCLUSÕES}

A Convenção Interamericana contra a Corrupção de 1997, adotada no âmbito da O.E.A., cobre um amplo elenco de atos corruptos, incluindo desde a corrupção puramente doméstica até a corrupção transnacional. Ela representa o primeiro tratado internacional abordando o tema da corrupção transnacional e a primeira iniciativa jurídica regional do mundo em desenvolvimento. É mais ampla em seu escopo do que o 
instrumento da O.C.D.E., já que requer legislação criminalizando os aspectos passivo e ativo da corrupção.

Por sua vez, os instrumentos legais adotados no âmbito da O.C.D.E. demonstram que os países desenvolvidos reconheceram que a corrupção de funcionários públicos estrangeiros produz efeitos adversos também nos países fornecedores de propinas. Entre estes efeitos, os referidos países reconheceram que a corrupção acarreta a perda de padrões morais, representando um sério atentado ao desenvolvimento e à preservação das suas próprias instituições democráticas, além de comprometer seriamente a confiança do cidadão nas instituições econômicas, distorcendo assim a competição internacional livre e justa. A corrupção é então condenada moralmente, socialmente e legalmente.

Como os maiores exportadores de bens, serviços e investimentos, as empresas transnacionais representam, de longe, a maior fonte de propinas. Por esta razão, a Convenção da O.C.D.E. sobre o Combate da Corrupção de Funcionários Públicos Estrangeiros em Transações Comerciais Internacionais de 1999 focaliza no lado ativo da corrupção. O seu escopo é interromper o fluxo internacional de propinas por meio de compromissos internacionais. Assim sendo, obriga as partes signatárias a adotarem legislações nacionais criminalizando a corrupção de funcionários públicos estrangeiros, incluindo a aplicação de penas severas. Embora a Convenção tenha sido concebida para atacar apenas um aspecto do problema complexo da corrupção - aquele referente ao fornecimento de propinas -, todavia, corrupção deve ser entendida como um fenômeno multifacetado que vai além da responsabilização criminal. Com o objetivo de combater a corrupção, os Estados deveriam desenvolver e implementar medidas adequadas para aumentar suas capacidades no tocante à prevenção, à detecção, à investigação, ao controle de práticas corruptas e ao aperfeiçoamento da cooperação internacional neste âmbito.

$\mathrm{Na}$ esfera da administração pública, aspectos mais amplos de governança deveriam ser incluídos, tais como reformas legais e judiciárias, e o fortalecimento da sociedade civil. Ademais, os governos deveriam tornar seus procedimentos transparentes e, onde apropriado, descentralizar as instituições públicas e os serviços e fortalecer a parceria dos setores público e privado com a sociedade civil. Os Estados deveriam ainda considerar os problemas causados pela corrupção transfronteiriça, em especial aqueles relativos às atividades econômicas das empresas transnacionais, além de estudar a adoção de medidas legislativas apropriadas para assegurar a transparência e a integridade dos sistemas financeiros e das transações daquelas empresas.

Naturalmente, estes dois instrumentos regionais representam um grande avanço no combate da corrupção transnacional. Devem abrir caminho para a futura celebração de um tratado internacional universal de combate à corrupção e de cuja negociação participem a grande maioria dos Estados soberanos, talvez no âmbito da Organização das Nações Unidas. Para isto, é verdade, deve-se chegar a uma definição ampla e universal do fenômeno. Na busca dessa definição ampla, o fato de que a corrupção requer dois atores, o provedor e o beneficiário, deve ser levado em consideração, assim como o fato de que a corrupção não ocorre somente no setor público, como também no setor privado. A Convenção da O.C.D.E. trata exclusivamente da corrupção "ativa" de 
funcionários públicos estrangeiros, em oposição à corrupção "passiva". Portanto, para os fins da Convenção, somente os agentes privados são os ofensores. Isso representa um esforço no sentido de eliminar o provimento de subornos para funcionários públicos estrangeiros, com cada país sendo responsável pelas atividades de suas empresas e pelo que acontece no âmbito de suas fronteiras territoriais. Já a Convenção da O.E.A. dirige-se à corrupção no desempenho de funções públicas, atacando portanto a corrupção ativa e passiva, tendo assim um escopo mais amplo que aquele do instrumento da O.C.D.E. sobre a corrupção de funcionários públicos estrangeiros. Entretanto, nenhuma delas aborda a incidência da corrupção no setor privado.

Como última observação, relembramos que de forma geral os instrumentos jurídicos internacionais não têm eficácia direta no âmbito estatal, já que dependem da implementação de legislação interna para que suas disposições sejam efetivamente aplicadas. Por outro lado, constituem exemplo da tendência legal contemporânea, onde uma certa medida de personalidade jurídica internacional é conferida aos indivíduos e às pessoas jurídicas de direito privado, as empresas transnacionais, já que normas convencionais de direito internacional são a eles dirigidas.

\section{REFERÊNCIAS BIBLIOGRÁFICAS}

Disponível em: http://www.magnet.undp.org.

Disponível em: http://www.oas.org.

Disponível em: http://www.oecd.org.

Disponível em: http://www.transparency.de.

Disponível em: http://www.un.org. 